\title{
Who Should Learn Proving and Why: An Examination of Secondary Mathematics Teachers' Perspectives
}

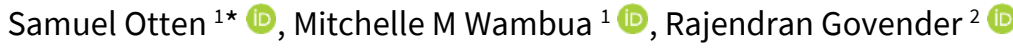

${ }^{1}$ University of Missouri, Columbia, MO, USA

${ }^{2}$ University of the Western Cape, SOUTH AFRICA

*Corresponding Author: ottensa@missouri.edu

Citation: Otten, S., Wambua, M. M., \& Govender, R. (2021). Who Should Learn Proving and Why: An Examination of Secondary Mathematics Teachers' Perspectives. International Electronic Journal of Mathematics Education, 16(3), em0662. https://doi.org/10.29333/iejme/11298

\begin{tabular}{|c|c|}
\hline ARTICLE INFO & ABSTRACT \\
\hline Received: 14 Apr. 2021 & Reasoning-and-proving is a crucial part of students' mathematical experiences in secondary school. There is \\
\hline Accepted: 14 Sep. 2021 & $\begin{array}{l}\text { scholarly debate, however, on the extent to which proving at the secondary level needs to be formal and whether } \\
\text { all students should be held to disciplinary standards of rigor. In this study, we investigated the notion of "proof for } \\
\text { all" from the perspective of secondary mathematics teachers. We analyzed, using the framework of practical } \\
\text { rationality, the justifications teachers gave for whether or not all students should learn proof. Based on interviews } \\
\text { with twenty-one secondary teachers from a socioeconomically-diverse set of schools, we found that teachers } \\
\text { differ in their opinions of who should learn proving but they were similar in their feelings of obligation toward } \\
\text { individual student learning; some teachers cited obligations to individual students as a justification for teaching } \\
\text { proving to all students and others cited those obligations as a justification for not teaching proving to some } \\
\text { students. We also share teachers' perspective with regard to their obligations to the discipline, educational } \\
\text { institutions, interpersonal dynamics among students, and the worldly relevance of mathematics education. }\end{array}$ \\
\hline
\end{tabular}

Keywords: reasoning and proof, teacher beliefs, high school education, equity and diversity

\section{INTRODUCTION}

\section{Motivation for Studying Perspectives on Who Should Learn Proving}

Reasoning-and-proving, the broad mathematical practice of conjecturing, justifying, critiquing arguments, constructing proofs and more (Stylianides, 2008), is central to the discipline of mathematics and can also be a powerful process through which students learn mathematics (de Villiers, 1995; Stylianides et al., 2017). Policymakers (National Governors Association \& Council of Chief State School Officers, 2010; Secretaría de Educación Pública, 2014) and scholars (e.g., Hanna, 1995; Mariotti, 2006) alike have called for reasoning-and-proving to be a part of all students' learning experiences in school. But there are also critiques of this general framing of learning "for all" such as Martin (2003) who pointed out that "for all" often comes as impositions on underserved groups, and Battey (2019) pointed out that "for all" can gloss over learners' individuality, proposing "for each and every" as a replacement framing. With regard to formal proof in particular, Weber (2015) noted that it may be unnecessary at the secondary level to explicitly develop "proving" and that it may be sufficient to push for clear explanations and valid justifications, which is one of the functions of proving (de Villiers, 1999) and may more clearly build upon students' mathematical experiences prior to secondary school.

Where do mathematics teachers, as the ones directly responsible for enacting curricular recommendations, stand on this issue of "proof for all"? How are teachers thinking about the scope and appropriateness of proof for students? Past studies have examined teachers' views of what proof is (e.g., Ko, 2010) and their views on mathematical processes including proof (e.g., Sanchez et al., 2015) but the question of who they think should learn proof is fundamental. In this study, we interviewed 21 secondary mathematics teachers from an economically-diverse set of schools in Cape Town, South Africa. Although Cape Town is a particular geographic and cultural context, it shares common traits with other parts of the world such as the heavy influence of European colonization and a tradition of mathematics instruction that is procedural and strategic in nature (Webb \& Roberts, 2017). Moreover, the question of who should experience proof is one with worldwide relevance as we broadly consider students' mathematical experiences.

\section{Personal Perspectives}

Because this study involves our analysis of teachers' perspectives on proving, it is important that we reveal salient information about our own perspectives for the sake of transparency. Samuel Otten is an American white man of Western European descent 
who attended rural public schools and then public universities where he earned degrees in both mathematics and mathematics education. Mitchelle Wambua is an African woman who attended the Kenyan elementary, secondary, and undergraduate education system, and is currently in the U.S. pursuing a doctoral degree in mathematics education. Rajendran Govender, an Indian born in South Africa, attended urban primary and secondary public schools during the apartheid era and then proceeded to study at public universities where he earned degrees in both mathematics and mathematics education.

Although from diverse backgrounds, we all share a view that proving-in the sense of constructing reasonably complete and logically-valid arguments for mathematical claims-is important for all students in the general education system as well as most students in the special education system. For us, it is not essential that this process be called "proof" or "proving" nor that all of the students' arguments be fully acceptable to professional mathematicians. But it is essential, in our opinions, that each and every student has opportunities to make a conjecture or explore a peer's conjecture and to experience how the process of justifying, critiquing, and refining reasoning can shed light on mathematical ideas and also build meaningful community. Holding these opinions, we nevertheless value hearing the voices of teachers and taking seriously their perceptions of what is possible and why. Indeed, we recognize that teachers' perspectives should carry more weight than our own because they are the ones actively working day to day with the students. Said another way, it is more important for us to learn about and respond to teachers' perspectives on proof than it is for them to hear our own.

\section{Theoretical Perspectives}

In terms of our approach to teachers' perceptions, we view teachers as participants in a cultural practice of teaching that is governed by norms (i.e., tacitly expected behaviors or unquestioned historical practices) and obligations (i.e., requirements perceived as inherent to their role as a mathematics teacher) (Herbst \& Chazan, 2011). Teachers have a "practical rationality" (Herbst \& Chazan, 2003) to their decisions and actions as they operate within a didactical contract (Brousseau, 1997). With this view in mind, we follow the recommendations of Herbst and Chazan to strive toward first understanding the teachers' professional reasons for doing things the way they do and valuing their voices and commitment to the cultural profession of teaching.

At the same time that we honor individual teachers' perspectives, we also recognize the cultural norms and obligations of teaching that influence teachers (see Herbst \& Chazan, 2011; Webel \& Platt, 2015). That is, teachers do not exclusively make autonomous decisions about their teaching; most teacher decisions are based on their interpretations of the obligations they are expected to meet. Herbst and Chazan (2011) add that the title "teacher" is an institutional title that comes with expectations from the institutions they work for. These expectations may pertain to teaching the school-mandated curriculum, preparing students for standardized tests, among others. Moreover, the title "mathematics teacher" denotes a role that encompasses the expectation to honor obligations of the profession of teaching mathematics and the students' learning of mathematics while also upholding the larger institutional obligations as discussed above.

Additionally, Erickson and Herbst (2018) warn that the process that teachers go through as rational professionals to make decisions about their teaching is not always smooth. Teachers operate under a larger 'ideal' model or rationality, which consists of social resources and constraints that influence their decisions and judgements. As a consequence, they may at times find these norms and obligations conflicting-they may want to do one thing, yet be "forced" by these cultural obligations to do something different. For example, in their study on teachers' justifications for whether they use whole-group discussions in their geometry classes or not, Erickson and Herbst found that some teachers who agree to be under institutional obligations to hold whole-class discussions, cited disciplinary obligations (i.e., the requirements of different mathematical topics and curriculum) for why they may not hold whole-class discussions.

Obligations, in particular, can be used to categorize the justifications that teachers provide for their instructional choices. Prior work has distinguished between disciplinary, individual, interpersonal, and institutional obligations (Herbst \& Balacheff, 2009; Herbst \& Chazan, 2011). We describe these categories in detail in the Method section, but for now we can consider some brief examples. A teacher may decide to present a proof to students rather than have them independently construct the proof because she feels an institutional obligation to complete the lesson in a single class period and stay "on pace" with a district pacing guide. Or a teacher may decide to emphasize formal terminology in a proof because they feel a disciplinary obligation to maintain mathematical "rigor." Teachers, while teaching proof, may also feel an obligation to promote student understanding (individual obligation) or to promote respectful classroom dialogues (interpersonal obligation).

\section{Research Questions}

With those perspectives as background and in the context of Cape Town, South Africa, this study focuses on two central research questions:

1. According to secondary mathematics teachers, who should learn proving in their formal mathematics education?

2. What professional obligations do secondary mathematics teachers reference when justifying their answer about who should learn proving?

Before describing our method and findings related to these questions, we share a brief review of literature as it relates to these research questions. 


\section{LITERATURE REVIEW}

\section{Calls for Students to Learn Proving in School}

Students have long had difficulties with proving (see Mariotti, 2006; Senk, 1985; Shongwe, 2020) but it is nevertheless seen as a worthwhile learning goal because of proof's importance to the discipline of mathematics (thus exerting a potential disciplinary obligation on teachers) and its potential to support deep learning (thus exerting a potential individual or institutional obligation on teachers). For these reasons and others, the mathematics education community has called for increases in proving opportunities. For example, in the United States, the National Council of Teachers of Mathematics (2000, 2009) has made proof, viewed as the formal endpoint of the reasoning process, a cornerstone of secondary mathematics and, in Japan, proof is explicitly expected from Grade 8 onward (MEXT, 2008). Many scholars have also called for proving to be included in the elementary grades, recognizing that those opportunities should be age appropriate while also authentic to the discipline of mathematics (e.g., Bieda et al., 2014; Krpan \& Sahmbi, 2020; Stylianides, 2007).

This widespread call from scholars and policymakers for all students to engage in proving goes back further than the modern era. Taking the United States as an example, in his historical review of the two-column proof, Herbst (2002) noted that students in the 19th Century were predominantly expected to read proofs, not produce them, and even this exposure was not required for all students. However, the Committee of Ten report (Eliot et al., 1969), published in 1893, marked a shift toward students' active proving as a centerpiece of high school Geometry and also an expectation that it be required for all students. The Committee of Ten recommended a fairly unified mathematics curriculum for all students, regardless of their future educational or career intentions. In the United States and elsewhere, the justifications for expecting proving from all secondary students included the notions that proving was central to mathematics (disciplinary obligation) and also that proving could help develop students' mental facilities with regard to reasoning and logic (individual obligation) (Kliebard \& Franklin, 2003; Stanic, 1987). These new expectations were challenging to enact and Herbst (2002) documented how the two-column proof format itself "had developed as a viable way for instruction to meet the demand that every student should be able to do proofs" (p. 285).

Herbst (2002) also pointed out that, more recently, this call that all students should learn proof has evolved into the notion that proof is not merely a topic to be covered but should be a process for discerning truth that is integrated into mathematical activity across the grades (see also NCTM, 2000). As shared in our personal perspectives above, this integrative view of proving is one that we share, yet we also recognize some drawbacks to these calls of proof for all. First, it remains true that teaching proof to all is a challenging endeavor and so can lead to feelings of failure and frustration. Second, deductive reasoning, if not done in an inclusive and careful manner, can perpetuate a Western, colonizing historical perspective with a privileging of the Greeks' historical traditions. Third, given many of the current systems of education that function as societal gatekeepers, proof instruction can exacerbate the role that mathematics plays in inequitably sorting and excluding students from future opportunities. In South Africa, for example, Shongwe (2020) found that greater school resources correlated with greater proof performance. This suggests that a danger of instituting proof for all would be that differential success with proving could be used as a status symbol and yet it is actually a reflection of the differential resources allotted to schools.

Some scholars have approached these complex issues by proposing a reframing of proof in secondary schools or even a reframing of the mathematics curriculum overall. For example, Gutiérrez (2017) proposed a re-focusing of school mathematics away from traditional (often Western, colonial) mathematics content and toward the inclusion of all students, various ways of knowing, and human joy. More specifically on the topic of reframing proof in school mathematics, Weber (2015) proposed that formal proof may not be necessary nor as effective as simply engaging students in ever-clearer explanations and thorough justifications. In this sense, explanations and justifications would be expected of all students, but it would not necessarily need to be called "proof" for all students. Relatedly, Conner (2018) and Otten et al. $(2014,2017)$ wrote about teaching proof in a way that invites all students into seeing the need and value of proving, rather than simply forcing proof as a requirement on all students.

These various perspectives from mathematics education scholars can be viewed as efforts to balance obligations to the individual learners, such as their motivation for learning and their empowerment as individual sensemakers, with the obligations to the discipline, and in some cases prioritizing the former over the latter or proposing a re-definition of the latter. The professional obligations, however, are predominantly felt by practicing teachers and thus it is important to bring their voices into this conversation about who should learn proving and in what way they should learn it.

\section{Research on Teachers' Perspectives}

There have been several past studies on teachers' conceptions of proof (e.g., Bleiler et al., 2014; Furinghetti, 2011; Knuth, 2002) and, extending from that work, it is possible that notions of what proving is relate to their justifications of why students should learn proving (or not). This is discussed below in relation to their justifications as presented in the findings. Even more relevant as context for the present study is research on teachers' perspective about teaching proof and who should learn it. Erickson and Herbst (2018), for example, investigated teachers' views on the ways in which proof should be taught, with a particular focus on the role of discussions in teaching and learning proof. They found that early career teachers highlighted the role of discussions as an aspect of proving that is integral to the negotiation of meaning. This contrasted with teachers later in their career who focused more on the individual development of proving skills. In both cases, there was rationality from the teachers in terms of various dynamics at play with regard to the teaching of proof.

With regard to who teachers think should learn proof, there is not a great deal of research. But Sears (2018) did conduct a study in a United States context. Sears found that most teachers want all students to engage in constructing proofs, but as this goal becomes a reality the teachers may reduce the demand of the proof tasks. For example, Sears described that, for cognitively- 
demanding proof tasks, "the teachers generally completed the task for the students and required students to take notes about the proof. Their actions generally sought to make the proof easier for students, in an effort to improve the likelihood that students will attempt the proof" (p. 176). From the perspective of our theoretical framework, this can be viewed as a tension between the disciplinary obligation of teaching proof (an important mathematical process that is worthwhile for all students) but also the individual obligation to student success (with the teachers perceiving their obligations as a need to help students avoid struggle).

Other research on teachers' perspectives focus more generally on teachers' beliefs about mathematics or about teaching mathematics. For instance, Beswick (2012) linked their mathematical beliefs to their general beliefs about teaching, but our work refines this link by looking at a specific aspect of teaching (namely, the teaching of proof) and their specific justifications and felt obligations. Another analysis of teachers' perspectives, by Lynch and Salikhova (2016), focused on teachers' general beliefs about students' needs. They found that teachers emphasized students' competence and meaning much more than student autonomy. In our interpretation, the teachers believed it was important for students to successfully develop skills and build understandings, and the downplaying of autonomy corresponds to a reduction in the chance of student struggles or failures. As we take these ideas into the realm of students learning proof, we see that students' success, and particularly the avoidance of struggle, is an important element of many teachers' perspectives. These individual obligations are balanced in different ways by different teachers in relation to the perceived value of proof as an obligation to the discipline.

\section{METHOD}

\section{Setting and Participants}

The study was conducted in the Cape Town metropolitan area of South Africa, which is a port city on the southwest coast. South Africa, since its democratization in the 1990s, has pursued curricular reforms centered on universal education (Webb \& Roberts, 2017). Its official standards call for elements of reasoning-and-proving to be taught to all learners so that they develop problem-solving skills, mental processes of "logical and critical thinking" (Department of Basic Education (DBE), 2007, p.8) and "the ability to be methodical, to generalize, make conjectures and try to justify or prove them" (p. 8). We conducted the study at five schools in this region. The schools were of varied socioeconomic status and the racial demographics of the students varied as well (see Table 1). For context, the Western Cape province has a median income of 30,000 ZAR annually ( $\$ 1,800$ USD) and approximately $36 \%$ Black African, $48 \%$ Coloured (the accepted South African term for multiracial individuals), and $16 \%$ white.

Table 1. School info. Textbooks may not be essential in this paper, but it might be slightly meaningful in terms of the school's orientation to curriculum

\begin{tabular}{|c|c|c|c|}
\hline School & Socioeconomic Status & Textbooks & $\begin{array}{l}\text { No. of Teacher } \\
\text { Participants }\end{array}$ \\
\hline Ramaker Girls & High & Platinum Classroom Maths & 2 \\
\hline South Shore & Semi-high & Classroom Maths, Mind Action & 8 \\
\hline Excellence & Mid & Classroom Maths & 6 \\
\hline Billings South & Semi-low & Classroom Maths, The New Solution for Revisions in Maths & 2 \\
\hline Science \& Technology Center (SATC) & Low & Platinum, Mind Action & 3 \\
\hline
\end{tabular}

From the five schools, a total of 21 teachers participated in this study. All mathematics teachers were invited to participate and the study was conducted with those who consented. This voluntary bias is not a threat to the study because our aim is to understand teachers' views and the nuances of their justifications and perceived obligations, with any teacher's perspective being as valid as any others, and our goal is not to provide a representative picture of mathematics teachers overall. The participating teachers had as their primary job responsibilities the teaching of mathematics to learners in grades 10-12, with some of them also teaching other subjects or working in school administrative positions. The participating teachers had varied experiences in terms of their professional preparation and years of teaching, with experience ranging from 3 years to 33 years (median $=10$ years). We refer to each of the teachers using a pseudo-surname.

\section{Data Collection}

The first author, sometimes with the third author, conducted two types of semi-structured interviews in English. All 21 teachers participated in group interviews that were organized by school and lasted for 20-40 minutes. There were a total of five group interviews, each consisting of two to eight participating teachers from the same school. These group interviews focused on the purposes of mathematics education and curricular issues related to proving. Questions included "when you were a student in math, what were your experiences learning proof?" and "is it important for students to learn proving?" with the latter being especially relevant for this particular study. Ten of the 21 teachers also participated in individual interviews that lasted for 10-30 minutes. The individual interviews focused on the teachers' experiences with proving in their teacher-preparation programs and in their professional work of teaching high school mathematics. The individual teacher interviews also focused in more detail than the group interviews on who the teachers think should learn proof and their reasons for that belief.

All interviews were audio recorded and then transcribed by an external transcription service. The author team then listened through each of the recordings again to verify and correct the transcriptions as necessary (e.g., correcting formal mathematical terminology, specifying portions that had been deemed unintelligible but could be heard upon closer inspection). The audio files and transcripts were imported into MaxQDA analysis software and synchronized with time codes for further analysis. 


\section{Data Analysis}

Our data analysis primarily involved coding both the individual and group interview transcripts. We first read through the entire transcripts and flagged any segments where there was discussion of students learning proof. Within these segments, we were then guided by the research questions to code for (1) which groups of students the teachers mentioned as the ones who should learn proof (or not) in their formal education, and (2) the justifications the teachers gave for mentioning those students. This coding occurred in two phases.

During phase 1, the first and second authors read through the flagged transcript segments and applied emergent codes related to the research questions. For RQ1 (who should learn proof?), it became readily apparent that some teachers expressed the sentiment that all students should learn proving. We coded other responses as not all students should learn proving, but we noticed that these not-all responses were expressed in different ways. Some teachers talked about the subset of students who should be expected to learn proving whereas other teachers talked about a subset of students who should not necessarily be expected to learn proving. Hence, we modified our RQ1 coding scheme to account for this positive/negative framing in the not-all responses. For RQ2 (why should they learn proof?), we again applied emergent codes based on the justifications teachers provided. These initial codes included the following as justifications for students to learn proving: to deepen their understanding of mathematics, to help them become better thinkers, to help them in answering test questions, because it is expected in higher mathematics, because it is a curriculum requirement. With regard to justifications for students not learning proof, the emergent codes were that it was too difficult a topic or that it caused unnecessary struggle and frustration for the students.

During phase 2 of analysis, we re-examined all the justification codes through the lens of practical rationality (Herbst \& Chazan, 2011), particularly the professional obligations. We adopted four professional obligations-disciplinary, institutional, interpersonal, and individual-as articulated by Herbst and Chazan (2011). A fifth obligation, which we termed worldly obligation, emerged from our data. This obligation emerged as we analyzed teachers' justifications for teaching proof to all or some groups of students due to the usefulness of proofs in areas that are outside of mathematics, for instance in disciplines like chemistry, physics, and business. Additionally, the worldly obligation is also related to the potential for proof to foster critical thinking in students' current and future daily, real-world experiences which the teachers expressed as separate from school expectations (institutional obligations), interactions with classmates (interpersonal obligations), or mathematical expectations (disciplinary obligations). We view worldly obligations, as expressed by these teachers, as still related to individual obligations because they typically talked about the students' benefits in life beyond mathematics, but it was distinct from the individual needs in the class or in learning the content in question, as described by Herbst and Chazan (2011). Moreover, we recognize the possibility of a worldly obligation that is not about the individual student's needs but rather the teacher's obligation to help produce a wellreasoned citizenry. Table 2 shows these obligation codes, their descriptions, and some examples of each.

Table 2. A coding scheme for teachers' justifications for why students should or should not learn proving

\begin{tabular}{|c|c|c|}
\hline Obligation & Code Definition & Code Examples \\
\hline Disciplinary & $\begin{array}{l}\text { Teachers' perceived obligations related to } \\
\text { mathematics as a subject area or discipline. }\end{array}$ & $\begin{array}{l}\text { - Proving is the "core" of mathematics. } \\
\text { - Proving represents the "rigor" of mathematics. }\end{array}$ \\
\hline Institutional & $\begin{array}{l}\text { Teachers' perceived obligations related to the } \\
\text { educational system and policies. }\end{array}$ & $\begin{array}{l}\text { - Proving is included in the school curriculum and standards. } \\
\text { - Proving is required on official assessments. }\end{array}$ \\
\hline Interpersonal & $\begin{array}{l}\text { Teachers' perceived obligations to balance the } \\
\text { needs of a diverse class of learners and managing } \\
\text { productive interactions. }\end{array}$ & $\begin{array}{l}\text { - Proving promotes respectful critique. } \\
\text { - Proving can increase the accessibility of a mathematical idea to many } \\
\text { different students. }\end{array}$ \\
\hline Individual & $\begin{array}{l}\text { Teachers' perceived obligations related to meeting } \\
\text { the needs and expectations of specific learners. }\end{array}$ & $\begin{array}{l}\text { - Proving can help learners gain deeper understanding. } \\
\text { - Proving can be difficult and I do not want to frustrate certain students. }\end{array}$ \\
\hline Worldly & $\begin{array}{l}\text { Teachers' perceived obligations related to the real- } \\
\text { world usefulness of what is being taught. }\end{array}$ & $\begin{array}{l}\text { - Proving is useful in other disciplines and careers beyond mathematics. } \\
\text { - Proving will help learners use logic and critical thinking in daily, real-life } \\
\text { situations. }\end{array}$ \\
\hline
\end{tabular}

Throughout the coding process, we coded the transcripts separately but had at least two people inspect each interview. We met regularly to clarify and reconcile any discrepancies in the coding, though generally there were no major discrepancies in the coding. The only reconciliations we made were related to RQ2 and involved, for example, (1) agreeing to assign the individual obligation code to sections that addressed issues concerning both the success and struggles of certain groups of students with proving, and (2) coding for two obligations within the same justification statement, for example, both disciplinary obligation and individual obligation would be coded when teachers claim that proving is the core of mathematics and they have a responsibility to help those students who wish to pursue higher-level mathematics.

Our primary analysis consisted of the work just described, but in reviewing teachers' responses we also noted that some teachers, during their answers about who should learn proving and why, also talked about the manner in which they teach proof. Additional portions of the interview, not flagged for detailed analysis in this study, focus more directly on the manner of teaching proof but with respect to RQ1 and RQ2 here, there was some relation between who teachers said should learn proof and the way in which they teach it or think it should be taught. So, during our analysis, we decided to keep track of this phenomenon. In particular, we noted that there were themes of active versus passive student experiences with proof. We mention these in the findings as they relate to all students or not all students being expected to learn proof.

Having completed the coding for RQ1 (all or not all students learning proof) and RQ2 (obligations within teachers' justifications), our analysis concluded by looking across the two research questions to see if there were patterns or themes with regard to the relationship between who teachers thought should learn proving and why they should learn it. We noted a variety of 
reasons and obligations at play for the teachers who expressed that all students should learn proof, but essentially only one underlying obligation that they cited for why some students should not learn proof. We present these findings in the next section.

\section{FINDINGS}

Of the 21 teachers in the study, 15 expressed opinions on the question of who should learn proving. The most common opinion, expressed by 10 teachers, was that all students should have an opportunity to learn proving. However, 5 teachers stated that some students should be exempted from the opportunity to learn proving (see Table 3). Other teachers (i.e., some who only participated in the group interviews) did not express a definitive opinion on this question, but the sections below provide findings with regard to the rationality that teachers shared. We did not detect a relationship between the opinions expressed about who should learn proving and the schools at which the teachers taught, nor to the experience level or demographics of the teachers, so we treat the opinions and perspectives as being individually bound.

Table 3. Summary of the number of teachers expressing who should learn proving and their justifications with some teachers providing multiple justifications

\begin{tabular}{lll}
\hline Who should learn proving? & Number of teachers & Obligations (number of instances) \\
\hline All students & 10 & Individual (9) \\
& & Worldly (6) \\
& & Disciplinary (2) \\
\hline Not all students & 5 & When expressed as "some should": \\
& & Worldly (3) \\
& Disciplinary (3) \\
& Individual (2) \\
& Institutional (1) \\
\cline { 2 - 2 } & When expressed as "some should not": \\
& Individual (6) \\
& Institutional (1) \\
\hline
\end{tabular}

\section{Teachers' Rationality for All Students Learning Proving}

Teachers who stated that all students should learn proving provided a variety of justifications for that position. The most common justification related to the teachers' obligation toward individual student learning, with some teachers seeing proving as important in promoting deep mathematical reasoning and understanding. Others cited worldly usefulness of proving in other subjects and contexts, and the rest pointed to their disciplinary obligations to mathematics.

Individual obligations. Teachers explained that proving can help all students understand mathematical content in deeper or more interconnected ways. For example, Panyanga said the following:

All of [the students] should know how we get to things, not just the application... I'll just make an example with Pythagoras' theorem. You find that they know how to use it but they don't really understand it properly [without proving it].

An implicit obligation here is for the teacher to support students in understanding mathematics "properly," not just execute applications, and proving is something that promotes an understanding of "how we get to things," that is, where the ideas come from and how they are justified. A similar point was raised by another teacher, Rhyan, who said about proving opportunities, "You have to give people space to experience the idea" because this helps them to move beyond just knowing "that a parallelogram has opposite sides equal" to understanding how that result connects with other pieces of knowledge in geometry.

Two other teachers expressed that the learning of proving is important for all students because it ensures that students can reason deeply about concepts. Kaylene said that "to prove something means that you thought about it" because proving promotes a "reasoning way of thinking." Additionally, Selisha stated that deep mathematical reasoning is important because, without it, "people can just throw out theorems and the [students] must just accept them." Selisha meant that proving helps students to be careful consumers of mathematical theorems who critically examine and reason about the theorems given to them before accepting them.

Some teachers, as they were expressing that they would like all students to learn proof, also acknowledged that proving is difficult for most students. Selisha, for instance, said that proving is "very difficult [but] it is quite important" for students to learn and that "it's something that they struggle with." A similar idea was raised by Mitchell who said that proving is challenging for students, but added that the challenge is productive because, "whether [they] are right or wrong, that's not the point. It gives them exercise" and makes the students to reason deeply. These teachers acknowledged that proving is challenging for students, but they did not see that as a reason for why students should not learn proofs. According to them, the deep mathematical reasoning supported by proving is an important part of the students' opportunities to learn and thus was part of their obligations as a mathematics teacher.

Worldly obligations. Other teachers, in justifying that all students should learn proving, looked beyond the classroom. Specifically, these teachers expressed a worldly obligation by connecting mathematical proving to students' current or future lives beyond school mathematics. For example, Portia said the following: 
To prove something is not just a mathematical skill, it's a skill in logic, it's a skill in trying to figure out and to validate your arguments. And that is not confined to only mathematics... I think it is a valuable skill and I think that everybody has the ability to do it. You don't need to say, 'Okay, this is exclusively for those who score high marks [in mathematics].'

Here, Portia posits proving as an important "skill" for all students that is useful to them both in mathematics classes and beyond. Moreover, Portia maintains that all students have the "ability" to engage in the proving skill and advocates that teachers should have all students "do" proving instead of limiting it to only the students who perform well in mathematics. Elsewhere, in maintaining that the proving skill is not limited to only mathematics classroom, Portia stated that once students learn the proving skill in mathematics classes, they will be able to "relate [it] to seemingly unrelated things" beyond school.

Other teachers who cited worldly obligations for why all students should learn proofs viewed it as important in developing general "critical thinking" within students. An example is two teachers, Panyanga and Wills, who said that all students should learn proving because it helps them to reason deeply about general life issues not related to mathematics. Specifically, Panyanga said that proofs "should be for everyone because they help in terms of critical thinking and being able to reason and argue about all those other things" while Wills said that learning proving "helps them (i.e., students) with a lot of understanding and critical development, especially when they get into more real-life situations." With this, Panyanga and Wills asserted that all students should learn proving because it helps in the development of critical thinking and understanding that helps students to reason deeply about general life concepts and argue their positions beyond mathematics. Another teacher, Inderani, reiterated that all students should learn proving because it is only then that, "they can apply it in their daily lives."

Some of the instances of worldly obligations were not as much about life in general as they were about proving having benefits in other subjects besides mathematics. Shabeer said that "being able to prove something in geometry, it helps you even being able to prove it in something unrelated to geometry." Similarly, Wills said that the proving skills that students acquire in mathematics will help them in "other streams such as the physics...[and] business stream." These teachers view proving as a skill that all students should learn due to its usefulness in disciplines beyond mathematics like natural sciences and professional disciplines like business studies.

Disciplinary obligations. Beyond individual and worldly obligations, which both center on the teachers' obligations to promote student success, there were also two teachers who cited disciplinary obligations as their justifications for why all students should learn proving. When asked if all students should learn proving, Wills said, "it is important for them to know... what a proof looks like and why we have proofs." When asked to clarify why it is important for all students to learn proof, Wills answered that it's important "because [of] mathematics." In saying this, Wills implied that he is obligated by the mathematics discipline to ensure that all students learn proofs and hence he thinks it is important for all students to learn proving. It is important to note that Will's response to the disciplinary obligation of teaching proof is via a passive teaching of proving as depicted by his idea of showing students "what a proof looks like" and telling them "why we have proofs." Another teacher, Rhyan, said that all students should learn proving because it is "the highest level of mathematics thinking." We take Rhyan's comment to mean that an authentic way to teach mathematics involves actively giving students opportunities to partake in high levels of thinking that accord with the discipline, and because proving is the highest level, it is important for all students to learn it.

Summary. Most teachers argued that all students to learn proving and their justifications mostly appealed to individual obligations to the students' mathematical learning and to worldly obligations in terms of the students' success beyond mathematics. The teachers viewed proving as crucial in ensuring high levels of mathematical thinking among students. Additionally, they desired for all students to learn proving because that would furnish them with critical thinking skills useful in navigating general life issues and in learning other school subjects. In two instances, teachers cited their disciplinary obligation to mathematics as the justification for teaching proof to all students. None of the teachers appealed to institutional obligations when justifying why all students should learn proving.

Although not a central part of our analysis, we note that these arguments for teaching proving to all students did not necessarily entail an active engagement by students in the various facets of proving. In fact, in several instances, as can be seen above and is discussed in the Discussion section, the obligations only required the teachers to expose proving to students. This passive exposure to proving, at least from the perspective of some teachers, is a rational way to navigate the obligations to teach proving and the challenges that come with doing so. Another way to navigate these challenges is to separate students so that proving is only required of some of them. Thus, we turn now to teachers who said that only some students should learn proof.

\section{Teachers' Rationality for Not All Students Learning Proving}

Although one teacher commented that, were it in her power, she would remove proof from the official curriculum, we focus in this section on the several teachers who stated that only certain groups of students should learn proof. A total of 5 teachers mentioned that some students should learn proving and others should not. These teachers gave several reasons for why proving was beneficial to only a certain subgroup of students. The two main obligations that arose from our analysis of why students should learn proof (when teachers phrased it in the positive sense) are disciplinary obligations and worldly obligations. Additionally, there was a single teacher alluding to individual obligations towards student enjoyment during proving and another one citing institutional obligations. That is, the obligations associated with teachers who spoke in the positive sense about some students learning proof were similar to the obligations that arose in the previous section where teachers were justifying the position that all students should learn proof. On the other hand, when teachers spoke in the negative sense about students who should not learn proving, their rationality was predominantly related to their individual obligation to meet students' needs, especially the needs related to student struggle.

In the sub-sections that follow, we focus first on the obligations that teachers mentioned when talking about some students learning proof, which echoes some of the findings described in the previous section, and then we conclude with the new findings 
related to the individual obligations that were prevalent for teachers who were justifying why some students should not be required to learn proof.

Disciplinary Obligations. Some teachers who said that only certain groups of students should learn proving gave disciplinary reasons for their claims. These teachers viewed proving as the "core" or the highest and deepest level of mathematics, but in contrast to the teachers who argued for all students to learn proving, they indicated that only certain students are expected to engage in this core practice. Most often these teachers specified that the students who should engage in this deepest level of mathematics are the ones who have already demonstrated a high level of understanding and performance in mathematics or who will be pursuing further mathematics in the future. For instance, Shannon mentioned the following:

$[P]$ roving is actually the core of mathematics. If ever you want to move up within mathematics and you want to be very good in mathematics, I think that is the core part that's when you truly understand. But now, I think that core part-this is my feeling-is for the selected few somehow. Majority are not able to get that deep, to get into it deeper and deeper.

Shannon stated that proving is an important part of mathematics and it is necessary for those who want to succeed and proceed in mathematical studies. The implication is that proving is necessary because of its central place in the discipline, but this only applies to the "selected few" and not the majority of students because the majority of students do not have the ability to understand proving and "get into it deeper and deeper." Elsewhere, Shannon provided more clarity about the subgroup of students he had in mind as he insisted that only some students should learn proving because, "if we ever bring in [proving] concepts to the table there's a small percentage of people at the table who are supposed to understand what is happening." Here, Shannon continued to argue that only a small number of students are supposed to learn proving because they are the only ones who understand it.

Like Shannon, Trevelyan also referred to proving as the "core" of what mathematics is, and stipulated that it is only for a subset of students, but Trevelyan's identification of that subset was subtly different than Shannon's. Trevelyan said that proof should be "for the other students who are going to do something with the mathematics... are going to go and study further with the mathematics because that's the core of what mathematics is." In this instance, a disciplinary obligation is again evident as the teacher argues that proof is an essential part of mathematics, but whereas Shannon specified a subgroup of students who should learn proof based on their ability to successfully delve deep into the reasoning, Trevelyan specified the subgroup based upon their future academic trajectories; proving is relevant for those who will pursue higher mathematics. Within the rationality of both teachers, proving is a core part of the discipline of mathematics, and in one case it should be taught to those who can handle it and in the other case it should be taught to those who will continue forward to study higher mathematics. Of course, there might be substantial overlap between these two groups but they are not necessarily the same groups.

Worldly Obligations. Trevelyan also alluded to worldly obligations when he was discussing his position that some students should learn proof based on their future direction in life, and he was joined in this theme by Shabeer. Both teachers referenced students' future plans after secondary school. For example, Shabeer said that "there is a certain group of students [who] should learn proofs and it depends...on what that student plans to do when he's done with school," while Trevelyan said that the students who should learn proving are the ones, "who are going to do something with the mathematics [and] are going to go and study further with the mathematics." This rationale was beyond a disciplinary obligation, however, because it also included students who would go into non-mathematical fields but ones that nevertheless benefitted from rigorous mathematical reasoning. As Trevelyan explained, the students who "are going into the sciences field" should learn proofs because of the interdependence between concepts in mathematics and those in the pure sciences. Specifically, Trevelyan said that, "with...physics and chemistry, the approaches might be different but [they need] the mathematics [proving concepts]." This intention of the teacher to help prepare students for life-after-school connects with the worldly obligation in our framework.

Shabeer, albeit from a different school building, made a similar point as Trevelyan. Shabeer alluded to a worldly obligation for teaching proof and, as with the disciplinary obligations that teachers applied to a successful subset of students, he stated that proof is necessary for "those learners who excel in [secondary mathematics proofs]" and added that these students "should be focusing on [proofs]" because that will help them to better understand the concepts and be able to apply them in their future work. Overall, the instances of worldly obligations involved teachers who claimed that only some students will pursue future academic and career endeavors that require knowledge of mathematical proofs, and hence it is only those learners who should learn proof.

Institutional obligation. Institutional obligations were not often cited in the context of these focal interview questions, but one teacher, Shabeer, did reference obligations to the standardized state assessments in his rationality about teaching proof. In particular, Shabeer said the following about the subgroup of students he believed should learn proof:

These students must see [the proving process] because then they can answer all the higher-order questions...that's what I want them to answer, not the questions that are the standard. I mean, if they are able to answer the higher-order questions, they will be able to get more marks. Because being able to answer a higher-order question where you actually understand what's going on means you'll obviously be able to answer the other questions ... to those learners that it does get to, I can see an improvement in their marks.

Shabeer expressed that students who learn proving should see proofs and the process of proving for themselves because that would help them when answering "higher-order questions" on tests. Because of the distinction that Shabeer makes between these kinds of questions and others that are "standard," we interpret "higher-order questions'" to refer to the proving questions that ask not just for a straightforward answer, but rather for a detailed proof or argument for why the answer is valid. Shabeer added 
that it is this kind of questions that he wants the students to answer because when they answer them correctly, "they will be able to get more marks" in tests. We see an alignment in Shabeer's justification for teaching proving to an institutional obligation to raise students' scores in standardized tests, but there is also a connection to individual obligations.

Individual Obligations. In the previous quote, Shabeer is not only referring to the state assessment but he also mentioned the students' own understanding. He said that students who are able to answer the higher-order questions "understand what's going on [and are] obviously able to answer the other questions." In another of his responses, Shabeer said that "those learners who excel in [math] should be focusing on the proofs because it'll help them understand actually most of the math much better." Herein, Shabeer presents proofs as useful in supporting deeper levels of understanding among the students, and thus to teach proof is helping to fulfill an obligation to support students' learning, and in his view this is a relevant approach for those who are already excelling in mathematics. Similarly, Shannon said that it is only "those top learners, average to above average learners" who can understand proofs and these are the only students who "will understand where things are coming from." So, Shannon is also citing an individual obligation as it relates to the subset of students who should learn proof.

Individual obligations were especially common within the justifications that teachers gave for the subset of students who should not be required to learn proof. Whereas the positively-framed subset had to do with the obligation to support individual learning and understanding, the negatively-framed subset was entirely about the obligation to help students avoid struggle and failure by relieving them of the proving burden. For example, when asked who should learn proof, Shannon said the following:

I think our students must learn proofs but not all the students. Because... with a particular class I can prove a theorem or I can do a proof. But with another particular class I will see that if I want to prove this theorem, I will do more harm than good... For those learners whom I can say they may be average to above average, yes. If we say, 'Let us prove it and let us use it,' they will acutely enjoy the proving and the using of the proof.

For Shannon, he wants to teach proof when the result, as he perceives it, is an enjoyment of learning and students who see the usefulness of the proof. He has identified these benefits as being attached to some "but not all" students. For the other students, he refers to proving as doing "more harm than good," which we interpret to refer to confusion and unproductive struggle that can occur when he teaches proving. At another point, Shannon said that proving can cause students to become "discouraged," and Shabeer mentioned that those who "shouldn't learn the proofs are those learners [who] at the beginning are struggling... it's not going to be worth it to learn the proofs." Although these teachers were from separate buildings, Shannon and Shabeer made similar points about teaching proof to students who were struggling as causing "more harm than good" or the effort is "not going to be worth it".

Another teacher, Panyanga, in an attempt to explain why proving is not for every student, said that, "if there's no foundation, proper foundation, then the proofs become very difficult for below-average learners." By saying this, Panyanga implied that some students lack the basic foundation that can help them to understand proof, which makes their learning of proof difficult and hence not worthwhile for them to engage with. This difficulty in understanding proof was cited by several teachers like Shannon who said that, "with some of the learners, if you want to start by the proof you lose them completely. They will think that this thing is too difficult, [they] can't handle it and you lose them completely." We interpret Shannon's argument to mean that students who do not initially understand proofs feel lost when they experience it in class and hence develop avoidance behaviors.

Shannon added that the best way for teachers to help students who struggle with proofs is by just passively showing the proofs to them. He said:

What I do with it at times to avoid causing confusion in my class or to avoid boredom. What I do at times is I might say, 'Okay, today we just want to use-this is the formula we are going to use. Let me show you how we are using the formula. Let us do this exercise using this formula.'

Herein, Shannon implied teachers should passively teach proofs to the students who are struggling with it so they do not lose interest. He added, however, that after the struggling group has passively learned the proofs, the teacher can "[actively] prove it later with other groups." In this excerpt, avoiding proof or teaching it passively were both rooted in individual obligations to help (some) students avoid struggle or help (some) students achieve understanding.

Summary. Although most teachers argued that proving should be taught to all students, five teachers expressed that proving is best suited for certain students. The students who they contended should learn proof were those who excel at school mathematics or those who plan to pursue future programs related to mathematics or science. They cited disciplinary and worldly obligations in justifying the value of teaching proof to these students, and one teacher also noted the importance of marks on standardized assessments (institutional obligation). As for the students who should not be required to learn proof, this subgroup was defined by the teachers as the students who struggle with mathematics in general or proving in particular and their rationality hinged on the obligation to support their students' individual success and avoid unproductive struggle or frustration. No teacher said that none of the students should learn proving.

\section{DISCUSSION}

Our goal was to recognize teachers' rationality because this is important as we attempt to work collectively to improve proof learning (even if that means possibly reframing what "proof" is in schools). As scholars, it is not safe to presume that all teachers necessarily view proving as worthwhile for all students, and although a majority of the teachers in our study did express support 
for all students learning proof, or at least being exposed to proof, there were several teachers who exempted some students from this expectation. Our findings suggest that teachers on both sides of the issue were deeply attuned to individual obligations. Thus, there may be an opportunity for common ground by framing proof as a way to support individual learning (e.g., Miyazaki et al., 2017). If scholars seek to garner support from the teachers who did not think proof was necessary for all students then it may be wise to specifically make the case that proving can be fruitful for "struggling" students. If this case is not convincing, it is rational that the teachers would continue to do what they feel is best for their students, which in their view may be to relieve them of an unnecessary burden that is proving.

We further discuss these issues of individual obligations and "struggles" below, but we also note overall that our findings suggest some possible risks in appealing to disciplinary and institutional obligations. If scholars focus on the role of proof in the discipline or the fact that proof may be included on high-stakes assessments, this may inadvertently send the message that proving is only for students who are on a pathway to higher mathematics or is only required by an external force, not inherently worthwhile. Although it was relatively rare in our data, the notion of worldly obligations may provide an opportunity to promote more universal buy-in for proof learning in a variety of courses and contexts. Or if teachers do not see the worldly value of proving, then we may, like Weber (2015), have to take seriously the notion that formal proof may not be the most productive approach to reasoning for all students.

\section{Individual Obligations: Teachers' Perspectives on Struggle and Teaching Proof}

Individual obligations-that is, teachers' felt the need to support the success and learning of their students as individualswas a predominant theme in our analysis. What especially stood out to us was the emphasis on individual students' understanding from those teachers who were justifying teaching proof to all students, with proof and reasoning being a way to enhance understanding, and the emphasis on avoiding students' struggles from those teachers who were justifying that not all students needed to learn proof. All five of the teachers who said not all students need to learn proof mentioned some version of avoiding or relieving struggle as a rationale. And recall that these five teachers had different backgrounds and were from different schools.

Students' struggles with proof were also noted by teachers who nevertheless stated that all students should learn proof. For example, Rhyan stated, "I don't believe that [proof] should be withheld from anybody" and that we should still teach it even when there are student struggles because, in his view, "I just don't think that people should give up because people aren't getting it." Thus, struggle with proof was a common concern across nearly all the teachers in our study. Indeed, struggle is a key issue in mathematics education generally, with scholars looking at the delicate balance of maintaining productive struggle (e.g., Baker et al., 2020; Hiebert \& Grouws, 2007) and how teachers' responses to students function to maintain or interrupt the productive struggle (Warshauer, 2015). In this study, although the recognition of struggle was a commonality, the teachers differed in their responses to that perceived struggle. One teacher, Mitchell, said that proofs were challenging to students "in a productive way," adding that students should still learn proofs because "whether [the students' answers] are right [or] wrong, that is not the point." The idea is to "give the [students] exercise." Among other teachers who argued for still teaching proof amidst the struggle, some voiced the opinion that the struggling students may simply be shown proofs rather than having to work their way actively through the challenges. For example, Panyanga said that all students should be "exposed to [proofs]" after which they can "choose whether they want to continue with that or not."

This response to students' proof struggles by shifting to a more passive learning experience can be viewed through the lens of practical rationality. It is a rational decision-a compromise between the obligation to at least expose all students to an important (or district-mandated) disciplinary practice while also navigating the obligation to promote student success rather than frustration or failure. Similar shifts in the face of student struggle have been observed with cognitively-demanding tasks in general (Tekkumru Kisa \& Stein, 2015) and also in relation to proving specifically (Sears, 2018). Recall that Sears studied the interplay between teachers attempting to adhere to a district pacing guide as they enacted proof tasks. She noted that teachers have the agency to adjust enactments as they navigate between pacing expectations and students' success in the moment. The teachers in her study "bartered the cognitive demand of proof tasks assigned for students to complete the proof" and when challenges arose, "the teachers posed lower levels of cognitive demand" or "the teachers completed the proof" (Sears, 2018, p. 181). That finding connects with the perspectives expressed by teachers in the present study, some of whom expressed that student struggles are $a$ justification for presenting proofs to students rather than having students engage fully in proving. An important nuance to consider further is the fact that Sears' analysis focused on enactment decisions in the moment of struggle, whereas the teachers in this study were talking in general terms about who should learn proof and how, so the teachers here sometimes phrased their remarks about struggling students as an identity marker (e.g., "below-average learners") or a group characteristic rather than as a response to particular students in particular moments.

Thus, our study has focused on teachers' answers to the question of "who should learn proving?" by primarily focusing on the curricular or course-taking level and what to recommend for students who may struggle with proof, but we also saw connections in our data to the more in-the-moment level of students who are struggling with proof during a lesson and some teachers describing how they respond by having them passively observe the teacher demonstrate proofs. We have approached these questions assuming that teachers will answer it by striving to balance various professional obligations. Another way to approach these questions is to briefly consider them from a historical perspective or a chronological perspective in terms of students' experiences with proving throughout the grade levels. For example, Herbst (2002) identified three eras in the school curriculum where students first were expected to reproduce proofs from the textbook, then later students were expected to be able to produce proofs for certain propositions, and then the current era where we expect (even if it is not always fully realized) that students engage actively in the complex practice of reasoning-and-proving. Perhaps another way to interpret the data we have presented is to consider whether teachers are taking stances that align with various eras of proof expectations. Teachers who argue for a passive experience, at least for some students, may have views that align with the earlier eras where exposure to proof 
was sufficient. Or teachers who argue that students destined for mathematical careers should be expected to engage in the full practice of reasoning-and-proving may be reflecting the current era but only for a select group of students. This full analysis is beyond the scope of this paper, but it may be worthwhile to consider that elements of past eras are still present and that we must also be humble about the fact that the current era is not the final era. There may be broad expectations shared by many mathematics education scholars that will seem outdated in the future.

\section{Comments on the Other Obligations}

Although individual obligations predominated in these interview data, we would also like to comment on some of the other obligations that arose. Worldly obligations was a new category that we added to the practical rationality framework, similar to Zhao (2020) who noticed instances of worldly obligations related to another mathematical practice, mathematical modeling. We recognized that supporting students to use reasoning later in their lives, outside of mathematics, is still related to a perceived obligation to individual students to help them thrive, yet we felt that the separate domain of "outside mathematics" was worth distinguishing from individual obligations that are focused on students' learning and experiences within the mathematics class. Worldly obligations were alluded to six times in relation to all students learning proof and also three times in relation to some students learning proof. These instances show that at least some of the teachers actively consider that the role of reasoning and proving might be able to play in students' reasoning beyond mathematics. Indeed, this is a topic that we have become more interested in ourselves with regard to the question of whether and how mathematical forms of reasoning can help promote valid logic and critical thinking in everyday life (Inglis \& Attridge, 2017) or in various activities related to democratic citizenship (Skovsmose, 1998). These appeals to worldly benefits seem as though they may have some resonance with teachers in terms of motivating proof instruction, and it could also be a lever for promoting the kinds of proof learning experiences that are more likely to cross into other domains rather than narrow proof experiences that are essentially only for mathematics education.

This brings us to disciplinary obligations. Past literature on teaching proof in secondary school often references the mathematics discipline as a motivating force (e.g., Hanna, 1995; Harel \& Sowder, 2007), but we were surprised to find that it was not a common justification for the teachers in our study. We only coded two instances of disciplinary obligations among the teachers who argued for proof being taught to all students, and only three instances for teachers who argued for proof to be taught to some students. (Disciplinary obligations were not cited by the teachers who argued for students to not be taught proof.) Although our study is certainly not representative of all secondary mathematics teachers, it does raise the possibility that a disciplinary-focused approach to motivating proof instruction may not be the most fruitful when working with teachers. In fact, there may be a risk in foregrounding the discipline. Our data from teachers who thought that only some students should learn proof revealed the danger that teaching proof because of its centrality in mathematics can be used as a justification for only teaching proof to those students who are on track to take higher mathematics courses or pursue a career related to mathematics. In this way, an emphasis on disciplinary obligations, even if intended to motivate all students to experience this important mathematical practice, may be perceived by teachers as a rationale for emphasizing proof only with those students who are pursuing higher mathematics. Further research is needed on these dynamics, and we think it would be particularly wise to look further at the role of teachers' own conceptions of proof (e.g., Boyle et al., 2015; Knuth, 2002) and how those perceptions are linked to their perspectives on who should learn proof.

The final category of obligations is institutional obligations, which were not often mentioned by teachers in this study. We only coded two instances of institutional obligations when justifying proof instruction, one related to some students learning proof and one related to some students not learning proof. We cannot conclude, however, that institutional obligations were diminished for these teachers. The context of the study, with an outside research team visiting the school and asking them for what they may have construed as an idealistic view on reasoning-and-proving instruction, may have played a role in backgrounding institutional demands. If an administrator or teacher leader from within the school had been leading the conversations, it may have cued more institutional obligations to come to the surface. Or if we had studied the teachers' actual practice rather than their general thoughts, this too might have involved more appeals to their institutional responsibilities. Other studies, such as Sears (2018), have shown that district expectations like pacing guides can play an important role in teachers' decisions about proof instruction.

\section{CONCLUSION}

Many mathematics education scholars (e.g., de Villiers, 1999; Mariotti, 2006; Miyazaki et al., 2017) have taken the position that all students, even those in elementary grades (Bieda et al., 2014; Stylianides, 2007), can and should learn mathematical proof. More than half of the teachers interviewed in our study expressed a similar sentiment about all students learning proof, but it was not a unanimous position. Some teachers said that proof was a topic best suited for upper-level grades, and other teachers stated that not all students should be expected to learn proof. The basis for students being exempted sometimes had to do with the students' abilities, as perceived by the teacher, or with the students' plans after secondary school. We think it is important to hear these perspectives and consider the obligations that teachers are responding to as they think of proof learning opportunities. These considerations can help us have more productive conversations and design more productive efforts if we wish to advance the goals of broader inclusion in proof.

Finally, we think it is important to bear in mind the findings of Shongwe (2020), who also worked in a South African context. Shongwe found that so-called proof ability was not evenly distributed across various schools but that students in well-resourced, high-socioeconomic-status schools were found to be more adept at proving than students in under-resourced, lowsocioeconomic-status schools. This finding suggests that contextual factors play into what we might naively assume to be student traits or "natural ability." Thus, it would be misguided to decide on students' opportunities to learn proof based on our perceptions 
of their "ability" at the secondary level when those perceived abilities may actually be a function of their school setting. Although we did not notice patterns in the teachers' responses across the varied school settings in this study, and although the teachers did not discuss the school's resources as a factor influencing their opinion on who should learn proof, there may be underlying conditions that are worth studying further in relation to proof learning.

Author contributions: All authors have sufficiently contributed to the study, and agreed with the results and conclusions.

Funding: This work was supported by the University of Missouri South African Education Program and the University of Missouri College of Education and Human Development.

Acknowledgements: We thank the teachers for sharing their perspectives and for their generosity of time.

Declaration of interest: No conflict of interest is declared by authors.

\section{REFERENCES}

Baker, K., Jessup, N. A., Jacobs, V. R., Empson, S. B., \& Case, J. (2020). Productive struggle in action. Mathematics Teacher: Learning and Teaching PK-12, 113(5), 361-367. https://doi.org/10.5951/mtlt.2019.0060

Battey, D. (2019, February). Building towards equity: Identifying and detailing mechanisms in undergraduate mathematics. Plenary presentation at the 22nd annual conference of the Special Interest Group of the Mathematical Association of America on Research in Undergraduate Mathematics Education, Oklahoma City, OK.

Beswick, K. (2012). Teachers' beliefs about school mathematics and mathematicians' mathematics and their relationship to practice. Educational Studies in Mathematics, 79(1), 127-147. https://doi.org/10.1007/s10649-011-9333-2

Bieda, K. N., Ji, X., Drwencke, J., \& Picard, A. (2014). Reasoning-and-proving opportunities in elementary mathematics textbooks. International Journal of Educational Research, 64, 71-80. https://doi.org/10.1016/j.ijer.2013.06.005

Bleiler, S. K., Thompson, D. R., \& Krajčevski, M. (2014). Providing written feedback on students' mathematical arguments: Proof validations of prospective secondary mathematics teachers. Journal of Mathematics Teacher Education, 17(2), 105-127. https://doi.org/10.1007/s10857-013-9248-1

Boyle, J. D., Bleiler, S. K., Yee, S. P., \& Ko, Y.-Y. (2015). Transforming perceptions of proof: A four-part instructional sequence. Mathematics Teacher Educator, 4, 32-70. https://doi.org/10.5951/mathteaceduc.4.1.0032

Brousseau, G. (1997). Theory of didactical situations in mathematics: Didactique des Mathematiques 1970-1990. Kluwer.

Conner, K. A. (2018). Developing secondary students' understanding of the generality and purpose of proof [Doctoral dissertation]. University of Missouri.

de Villiers, M. D. (1995). An alternative introduction to proof in dynamic geometry. MicroMath, 11(12), 14-19.

de Villiers, M. D. (1999). Rethinking proof with the Geometer's Sketchpad. Key Curriculum Press.

Department of Basic Education. (2011). National curriculum statement grades R-12. http://www.education.gov.za

Eliot, C., Harris, W. T., Angell, J. B., Tetlow, J., Taylor, J. M., Robinson, O. D., Baker, J., Jesse, R., McKenzie, J., \& King, H. (1969). Report of the Committee of Ten to the National Education Association. In National Education Association, Report of the Committee on secondary school studies. Arno Press. (Original work published 1893).

Erickson, A., \& Herbst, P. (2018). Will Teachers Create Opportunities for Discussion when Teaching Proof in a Geometry Classroom? International Journal of Science and Mathematics Education, 16(1), 167-181. https://doi.org/10.1007/s10763-016-9764-4

Furinghetti, F., \& Morselli, F. (2011). Beliefs and beyond: Hows and whys in the teaching of proof. ZDM Mathematics Education, 43(4), 587-599. https://doi.org/10.1007/s11858-011-0316-7

Gutierrez, R. (2017). Living mathematx: Towards a vision for the future. In E. Galindo, \& J. Newton (Eds.), Proceedings of the 39th annual meeting of the North American Chapter of the International Group for the Psychology of Mathematics Education (pp. 226). Hoosier Association of Mathematics Teacher Educators.

Hanna, G. (1995). Challenges to the importance of proof. For the Learning of Mathematics, 15(3), $42-49$. http://www.jstor.org/stable/40248188

Harel, G., \& Sowder, L. (2007). Toward comprehensive perspectives on the learning and teaching of proof. In F. K. Lester, Jr. (Ed.), Second handbook of research on mathematics teaching and learning (pp. 805-842). Information Age Publishing.

Herbst, P. G. (2002). Establishing a custom of proving in American school geometry: Evolution of the two-column proof in the early twentieth century. Educational Studies in Mathematics, 49(3), 283-312. https://doi.org/10.1023/A:1020264906740

Herbst, P., \& Balacheff, N. (2009). Proving and knowing in public: The nature of proof in a classroom. In D. A. Stylianou, M. L. Blanton, \& E. J. Knuth (Eds.), Teaching and learning proof across the grades: A K-16 Perspective (pp. 40-63). Routledge. https://doi.org/10.4324/9780203882009-3

Herbst, P., \& Chazan, D. (2003). Exploring the practical rationality of mathematics teaching through conversations about videotaped episodes: The case of engaging students in proving. For the Learning of Mathematics, 23(1), 2-14.

Herbst, P., \& Chazan, D. (2011). Research on practical rationality: Studying the justification of actions in mathematics teaching. The Mathematics Enthusiast, 8, 405-462.

Hiebert, J., \& Grouws, D. A. (2007). The effects of classroom mathematics teaching on students' learning. In F. K. Lester, Jr. (Ed.), Second handbook of research on mathematics teaching and learning (pp. 371-404). Information Age Publishing. 
Inglis, M., \& Attridge, N. (2017). Does mathematical study develop logical thinking? Testing the Theory of Formal Discipline. World Scientific. https://doi.org/10.1142/q0020

Kliebard, H. M., \& Franklin, B. M. (2003). The ascendance of practical and vocational mathematics, 1893-1945: Academic mathematics under siege. In G. M. A. Stanic, \& J. Kilpatrick (Eds.), A history of school mathematics (pp. 399-440). National Council of Teachers of Mathematics.

Knuth, E. J. (2002). Secondary school mathematics teachers' conceptions of proof. Journal for Research in Mathematics Education, 33(5), 379-405. https://doi.org/10.2307/4149959

Ko, Y. Y. (2010). Mathematics teachers' conceptions of proof: Implications for educational research. International Journal of Science and Mathematics Education, 8, 1109-1129. https://doi.org/10.1007/s10763-010-9235-2

Krpan, C. M., \& Sahmbi, G. (2020). Argumentation is elementary: The case for teaching argumentation in elementary mathematics classrooms. In Mathematics (Education) in the Information Age (pp. 37-52). Springer. https://doi.org/10.1007/978-3-030-591779_3

Lynch, M. F., \& Salikhova, N. R. (2016). Teachers' conceptions about the child's developmental needs: A structural analysis. International Electronic Journal of Mathematics Education, 11(5), 1471-1479. https://www.iejme.com/download/teachersconceptions-about-the-childs-developmental-needs-a-structural-analysis.pdf

Mariotti, M. A. (2006). Proof and proving in mathematics education. In Á. Gutiérrez \& P. Boero (Eds.), Handbook of research on the psychology of mathematics education: Past, present and future (pp. 173-204). Sense Publishers. https://doi.org/10.1163/9789087901127_008

Martin, D. B. (2003). Hidden assumptions and unaddressed questions in Mathematics for All rhetoric. The Mathematics Educator, 13(2), 7-21.

MEXT (Ministry of Education, Culture, Sports, Science and Technology). (2008). Course of study section 3 mathematics 9 (in Japanese; $\quad$ published in English in 2011). http://www.mext.go.jp/component/a_menu/education/micro_detail/__icsFiles/afieldfile/2011/04/11/1298356_4.pdf

Miyazaki, M., Fujita, T., \& Jones, K. (2017). Students' understanding of the structure of deductive proof. Educational Studies in Mathematics, 94(2), 223-239. https://doi.org/10.1007/s10649-016-9720-9

National Council of Teachers of Mathematics. (2000). Principles and standards for school mathematics.

National Council of Teachers of Mathematics. (2009). Focus in high school mathematics: Reasoning and sense making.

National Governors Association \& Council of Chief State School Officers. (2010). Common core state standards for mathematics.

Otten, S., Bleiler-Baxter, S. K., \& Engledowl, C. (2017). Authority and whole-class proving in high school geometry: The case of Ms. Finley. The Journal of Mathematical Behavior, 46, 112-127. https://doi.org/10.1016/j.jmathb.2017.04.002

Otten, S., Gilbertson, N. J., Males, L. M., \& Clark, D. L. (2014). The mathematical nature of reasoning-and-proving opportunities in geometry textbooks. Mathematical Thinking and Learning, 16, 51-79. https://doi.org/10.1080/10986065.2014.857802

Sanchez, W. B., Edenfield, K. W., Lischka, A. E., \& Gammill, R. (2015). An emergent framework: Views of mathematical processes. School Science and Mathematics, 115, 88-99. https://onlinelibrary.wiley.com/doi/pdf/10.1111/ssm.12103

Sears, R. (2018). The implications of a pacing guide on the development of students ability to prove in geometry. International Electronic Journal of Mathematics Education, 13(3), 171-185. https://doi.org/10.12973/iejme/3835

Secretariá de Educación Pública. (2014). Secundaria, programas de studio [Secondary, study programs]. https://www.gob.mx/sep/acciones-y-programas/secundaria-programas-de-estudio

Senk, S. L. (1985). How well do students write geometry proofs? Mathematics Teacher, 78, $448-456$. https://doi.org/10.5951/mt.78.6.0448

Shongwe, B. (2020). Grade 11 students' proof construction ability in relation to classroom resources. International Electronic Journal of Mathematics Education, 15(2), 1-15. https://doi.org/10.29333/iejme/6278

Skovsmose, O. (1998). Linking mathematics education and democracy: Citizenship, mathematical archaeology, mathemacy and deliberative interaction. ZDM Mathematics Education, 30(6), 195-203. https://doi.org/10.1007/s11858-998-0010-6

Stanic, G.M.A. (1987). Mathematics education in the United States at the beginning of the twentieth century. In T. Popkewitz (Ed.), The formation of school subjects: The struggle for creating an American institution (pp. 135-175). Falmer.

Stylianides, G. J. (2008). An analytic framework of reasoning-and-proving. For the Learning of Mathematics, 28(1), 9-16.

Stylianides, G. J., Stylianides, A. J., \& Weber, K. (2017). Research on the teaching and learning of proof: Taking stock and moving forward. In J. Cai (Ed.), Compendium for research in mathematics education (pp. 237-266). National Council of Teachers of Mathematics.

Tekkumru Kisa, M., \& Stein, M. K. (2015). Learning to see teaching in new ways: A foundation for maintaining cognitive demand. American Educational Research Journal, 52(1), 105-136. https://doi.org/10.3102/0002831214549452

Warshauer, H. K. (2015). Productive struggle in middle school mathematics classrooms. Journal of Mathematics Teacher Education, 18(4), 375-400. https://doi.org/10.1007/s10857-014-9286-3

Webb, P., \& Roberts, N. (Eds.). (2017). The pedagogy of mathematics in South Africa: Is there a unifying logic? MISTRA and Real African Publishers. 
Webel, C., \& Platt, D. (2015). The role of professional obligations in working to change one's teaching practices. Teaching and Teacher Education, 47, 204-217. https://doi.org/10.1016/j.tate.2015.01.007

Weber, K. (2015). Episode 1519: Weber's review of justification and proof [Podcast]. Math Ed Podcast. https://www.podomatic.com/podcasts/mathed/episodes/2015-11-16T07_01_19-08_00

Zhao, W. (2020). Examining secondary teachers' practical rationality of mathematical modeling [Doctoral dissertation]. University of Missouri, Columbia, MO. 